\title{
The North Atlantic Oscillation and plankton dynamics in two European lakes - two variations on a general theme
}

\author{
DIETMAR STRAILE* and RITA A DRIA N † \\ *Limnologisches Institut, Universität Konstanz, D-78457 Konstanz, Germany, +Institut für Gewässerökologie und \\ Binnenfischerei im Forschungsverbund Berlin e.V., Müggelseedamm 260, D-12562 Berlin, Germany
}

\begin{abstract}
Long-term data on water temperature, phytoplankton biovolume, Bosmina and Daphnia abundance and the timing of the clear-water phase were compared and analysed with respect to the influence of the North Atlantic Oscillation (NAO) in two strongly contrasting lakes in central Europe. In small, shallow, hypertrophic Müggelsee, spring water temperatures and Daphnia abundance both increased more rapidly than in large, deep, meso/oligotrophic Lake Constance. Because of this, the clear-water phase commenced approximately three weeks earlier in Müggelsee than in Lake Constance. In Müggelsee, the phytoplankton biovolume during late winter/early spring was related to the NAO index. In Lake Constance, where phytoplankton growth was inhibited by intense downward mixing during all years studied, this was not the case. However, in both lakes, interannual variability in water temperature, in Daphnia spring population dynamics and in the timing of the clear-water phase, were all related to the interannual variability of the NAO index. The Daphnia spring population dynamics and the timing of the clear-water phase appear to be synchronized by the NAO despite large differences between the lakes in morphometry, trophic status and flushing and mixis regimes, and despite the great distance between the lakes $(\sim 700 \mathrm{~km})$. This suggests that a great variety of lakes in central Europe may possibly have exhibited similar interannual variability during the last 20 years.
\end{abstract}

Keywords: Daphnia, lake trophy, long-term time series, meteorological forcing, North Atlantic Oscillation, Population dynamics, seasonal succession

\section{Introduction}

The North Atlantic Oscillation (NAO) is a major source of interannual variability of weather and climate around the Northern Hemisphere (Hurrell \& van Loon 1997). Increased air temperatures during winter over much of Europe in the late 1980s and early 1990s are related to an extreme phase of the NAO with anomalously low pressures near Iceland and anomalously high pressures across the subtropical Atlantic (Hurrell 1995; Hurrell \& van Loon 1997). Changes in the abundances of phytoplankton (Reid etal. 1998; Belgrano etal. 1999), and copepods (Fromentin \& Planque 1996) in the Atlantic, and in the abundances of macrofauna off Norderney Island (Kröncke et al. 1998) and the Swedish west coast

Correspondence: Dietmar Straile, fax +497531 883533, e-mail dietmar.straile@uni-konstanz.de
(Tunberg \& Nelson 1998) have been linked with changes in the NAO. A strong connection between the NAO and the timing of seasonal succession events in the pelagic food-web of a large continental lake, Lake Constance, was established recently (Straile \& Geller 1998a). Higher epilimnetic water temperatures in spring in years with a high NAO index resulted in faster growth and higher spring biomasses of daphnids (Straile \& Geller 1998a), which in turn caused an earlier suppression of algae in Lake Constance (Straile 2000). The effects of winter temperatures on plankton dynamics have been studied in small lakes in Berlin (Adrian etal. 1995; Adrian \& Deneke 1996; Adrian 1997; Adrian et al. 1999). Although interannual differences in winter temperatures were not linked directly to the NAO by Adrian and coworkers, the occurrence of warm winters during the late 1980s and 


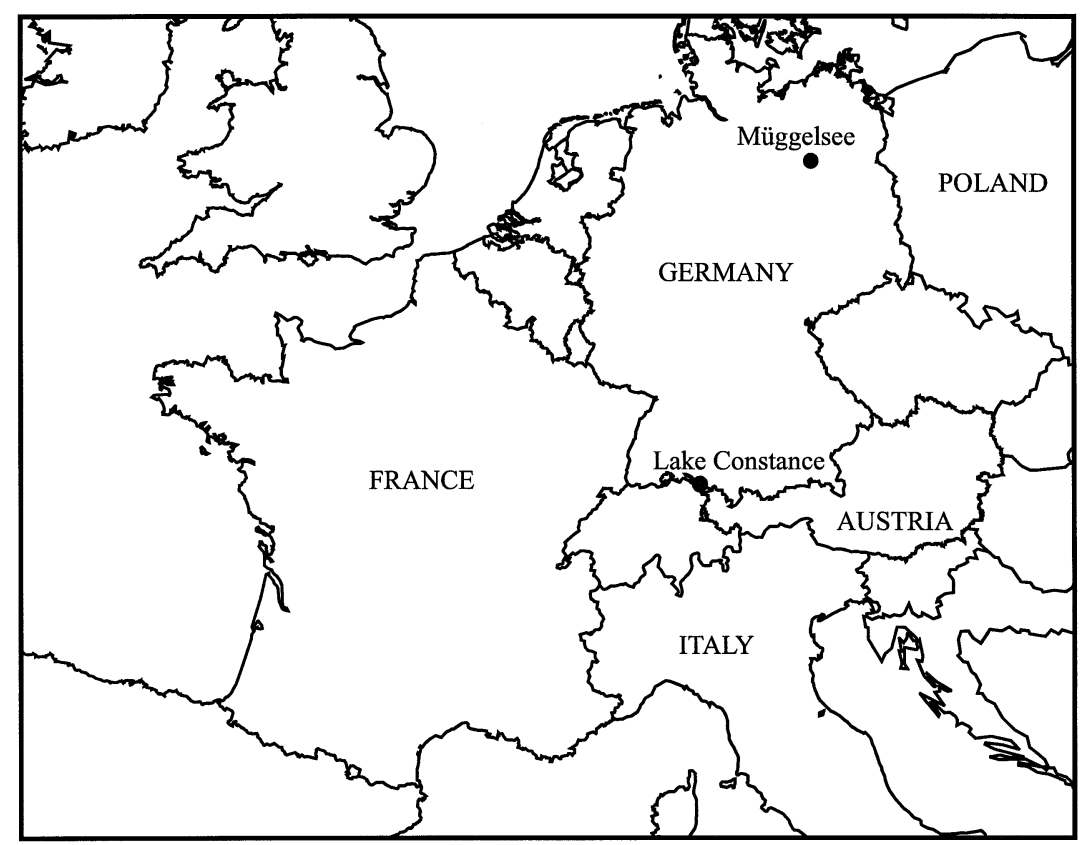

Fig. 1 Map showing the location of Lake Constance and Müggelsee. early 1990s suggests an influence of the NAO in the Berlin region also. That is, Lake Constance and the small and shallow lakes in Berlin seem to be influenced by the same large-scale meteorological signal.

Here we study the temporal coherence in the timing of seasonal succession events between Lake Constance and Müggelsee, two European lakes, which differ considerably in morphology and trophic status. We analyse the effects of the NAO on air and water temperatures, phytoplankton biovolume, Bosmina and Daphnia abundance in both lakes and examine to what extent interannual differences during spring in Müggelsee and Lake Constance could have been synchronized by the NAO.

\section{Study sites and methods}

\section{Study sites}

Müggelsee $\left(52^{\circ} 26^{\prime} \mathrm{N}, 13^{\circ} 39^{\prime} \mathrm{E}\right)$ and Lake Constance $\left(47^{\circ} 36^{\prime} \mathrm{N}, 9^{\circ} 25^{\prime} \mathrm{E}\right)$ are situated approximately $700 \mathrm{~km}$ apart (Fig. 1). Physicochemical aspects and the food webs of both lakes have been studied thoroughly during the last few decades [see the recent monographs on Müggelsee (Driescher etal. 1993) and Lake Constance (Bäuerle \& Gaedke 1998)]. Lake Constance is 20 times deeper and 60 times larger than Müggelsee, and its residence time is approximately 40 times greater than that of Müggelsee (Table 1). In addition, the lakes differ strongly in trophic status and mixing regime. Data series of air and water temperatures and phytoplankton and zooplankton composition and abundances dating back to
1979 are available for both lakes. For our analysis we use the time span from 1979 to 1994 because plankton dynamics in Lake Constance changed strongly after 1994 due to an ongoing decline in nutrient concentrations (Straile, unpubl. data).

\section{NAO index and measurements of water and air temperatures}

In this study we have used the NAO index (Dec. - March mean) provided by the National Center of Atmospheric Research, Boulder, USA (available on-line at http:// www.cgd.ucar.edu/cas/climind/nao_winter.html). It is based on the differences in normalized sea-level pressures between Lisbon, Portugal and Stykkisholmur, Iceland (Hurrell 1995). Müggelsee water temperatures were recorded at daily intervals at $0.5 \mathrm{~m}$ depth near the northern shore of the lake. Due to the polymictic character of the lake, the temperature at $0.5 \mathrm{~m}$ depth is close to the average temperature of the water column. Until 1993 temperature was measured using mercury thermometers; thereafter a temperature transducer was used for in situ monitoring. In Lake Constance, water temperatures at various depths were recorded on the plankton sampling dates (see below) in 1979, 1980, 1981 and 1986 and quasi-continuously (every $20 \mathrm{~min}$ ) during the other years. To allow a meaningful comparison with the shallow Müggelsee, we use the mean water temperature of the uppermost $8 \mathrm{~m}$ of the water column. Air temperatures were measured at the nearby meteorological stations of Berlin-Schönefeld and Konstanz and provided by the German weather service. 
Table 1 Morphological and limnological characteristics of the study lakes

\begin{tabular}{lll}
\hline & Lake Constance & Müggelsee \\
\hline Mean depth & $101 \mathrm{~m}$ & $4.9 \mathrm{~m}$ \\
Maximum depth & $253 \mathrm{~m}$ & $8 \mathrm{~m}$ \\
Area & $473 \mathrm{~km}^{2}$ & $7.3 \mathrm{~km}^{2}$ \\
Residence time & $4.2 \mathrm{y}$ & $40 \mathrm{~d}$ \\
Trophic state & meso/oligotrophic & hypertrophic \\
Mixis regime & monomictic & polymictic \\
\hline
\end{tabular}

Sampling of phytoplankton and zooplankton in Müggelsee

Plankton samples were taken at biweekly (zooplankton from 1979 to 1986) or weekly (zooplankton from 1987 to 1994, phytoplankton from 1979 to 1994) intervals during the vegetation period and at least once per month during winter using a 5-L Friedinger Sampler (HydroBios Apparatebau GmbH, Kiel, Germany). From 1979 to 1987 samples were taken from the deepest point at 1-m depth intervals. From 1988 to 1994 spatial heterogeneity was taken into account by sampling at five different sites (for details see Driescher etal. 1993). Phytoplankton samples were fixed with Lugol's solution and cell numbers and volumes were determined using an inverted microscope. Zooplankton samples were screened through a $50-\mu \mathrm{m}$ mesh and fixed with formaldehyde ( $4 \%$ final concentration).

\section{Sampling of phytoplankton and zooplankton in Lake Constance}

Plankton samples were taken weekly during the vegetation period and approximately biweekly during winter at the deepest point $(z=147 \mathrm{~m})$ of the north-western fjordlike arm of Upper Lake Constance (Überlinger See) from 1979 to 1994 . No zooplankton samples were taken during 1983 and no phytoplankton samples during July December 1983. Phytoplankton was sampled from the upper $20 \mathrm{~m}$ of the water column at 2-m intervals, using a 2-m long tube sampler, and further processed as described above. Zooplankton were collected using a Clarke-Bumpus sampler (mesh size $140 \mu \mathrm{m}$ ) by vertical hauls from $140 \mathrm{~m}$ depth.

\section{Statistical analysis}

Time-series of phytoplankton biovolume, Bosmina and Daphnia were logarithmically transformed. All timeseries were smoothed by calculating four-week moving averages within each year; for example, average Daphnia abundances for week 1-4 in 1979, week 2-5 in 1979 ... week $49-52$ in $1979, \ldots$, week $1-4$ in 1994, week $2-5$ in 1994, ..., week 49-52 in 1994. Then Pearson correlation coefficients were calculated between the NAO index and the respective mean values of each four-week period. The resulting correlograms express the response windows of each parameter to winter and spring conditions as expressed by the NAO index. To account for autocorrelation in the dependent and independent variables, we adjusted degrees of freedom according to the formulation given by Bartlett (1946): $N^{\prime}=N[(1-$ $\left.\left.a_{1} a_{2}\right)\left(1+a_{1} a_{2}\right)\right]$, where $N$ is the number of paired observations, $a_{1}$ is the degree of first-order autocorrelation in the dependent variable and $a_{2}$ is the degree of first-order autocorrelation in the independent variable. If one series is negatively autocorrelated, this correction can lead to an increase of the degrees of freedom. To avoid this, we set $N^{\prime} \leqslant N$ (sensu Post \& Stenseth 1998).

Because interannual variability of phytoplankton biovolume in the Müggelsee is strongly enhanced by the occurrence of massive blooms of cyanobacteria (Nixdorf \& Hoeg 1993), phytoplankton biovolume in Müggelsee was analysed both including and excluding cyanobacteria. The timing of the clear-water phase in both lakes was defined as the date of minimum algal biovolume after the spring phytoplankton maximum. Statistical analysis was performed using SAS (SAS Institute 1988).

\section{Results}

\section{Seasonal variability}

Seasonal variations in monthly air temperatures at Berlin and Konstanz during the study period were roughly similar (Fig. 2a). Only during March were air temperatures at Konstanz significantly higher than at Berlin (Pairwise $t$-test, $P<0.005)$. Mean water temperatures in Müggelsee were lower in winter and showed a faster spring warming and autumn cooling than water temperatures in Lake Constance (Fig. 2b). Phytoplankton biovolume in Müggelsee exceeded that in Lake Constance by almost one order of magnitude (Fig. 2c) and its spring maximum occurred during April, i.e. one month earlier than in Lake Constance (Fig. 2c). Phytoplankton biovolume showed a higher variability in February and March as compared to Lake Constance. Within both lakes, algal biovolume decreased during early summer and exhibited a summer maximum in July/August. Average Bosmina abundance in the two lakes was roughly similar during the winter months (Fig. 2d), but was higher in Müggelsee during summer and autumn. Additionally, the spring increase in Bosmina abundance was more pronounced in Müggelsee than in Lake Constance. In contrast, abundances and seasonal 

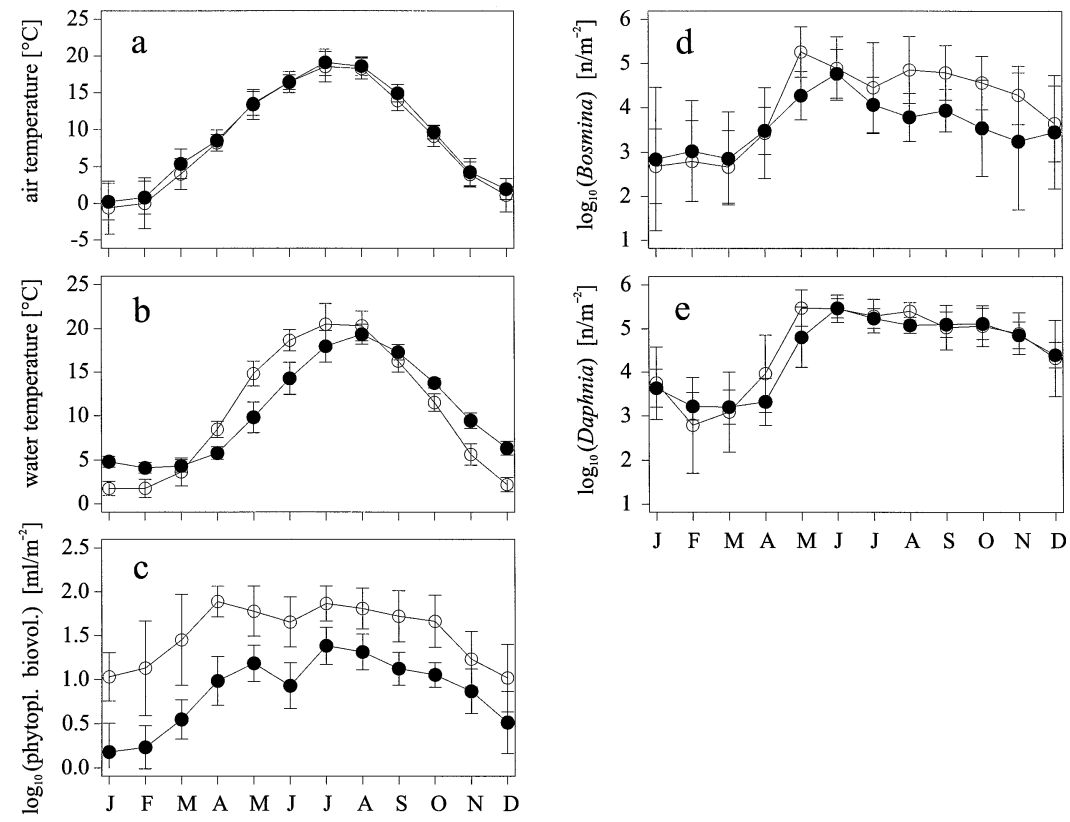

variations of Daphnia were much the same in both lakes, with the exception of an earlier vernal increase of Daphnia numbers in Müggelsee than in Lake Constance (Fig. 2e). Note that algal biovolumes and abundances of Daphnia and Bosmina in Fig. 2 are expressed per unit area, implying that Daphnia abundances per unit volume are higher in Müggelsee than in Lake Constance.

\section{Correlations with the NAO index}

Air temperatures in Konstanz in January, March and during a period in July/August were significantly correlated with the NAO index (Fig. 3a). Air temperatures in Berlin were strongly related to the NAO index during the first three months of the year and occasionally also later in the year. At both lakes correlation coefficients declined during April. In contrast, correlation coefficients between average water temperatures and the NAO index remained high until May in both lakes (Fig. 3b). Even though correlation coefficients declined gently in April in both lakes, they stayed $>0.4$ and were still significant at $P<0.1$. In Lake Constance, positive correlation coefficients were also obtained in July/ August (Fig. 3b). Total phytoplankton biovolume was positively related to the NAO index in Müggelsee during two periods in February/March and in June/July, but negatively during a period in October/November (Fig. 3c). Considering only eukaryotic phytoplankton, i.e. omitting cyanobacteria, significant negative correlations were also evident in April/May in Müggelsee. In contrast, phytoplankton biovolume in Lake Constance was not significantly related to the NAO index during the first half of the year, and only occasionally thereafter
Fig. 2 Mean seasonal variations of (a) air temperature (b) water temperature (c) phytoplankton biovolume (d) Bosmina abundance and (e) Daphnia abundance in Müggelsee (circles) and Lake Constance (dots) during 1979-94.
(Fig.3c). A similar picture emerged for Bosmina, whose abundances in spring were significantly related to the NAO in the case of Müggelsee but not in the case of Lake Constance (Fig.3d). Bosmina in Lake Constance was negatively correlated with the NAO index during July and August. In contrast, Daphnia abundances in both lakes during April/May were positively related to the NAO index (Fig. 3e).

The seasonal timing of significant correlations differed strongly among the analysed variables (Fig.4). In Müggelsee, a clear seasonal sequence emerged with positive correlations of the NAO index with phytoplankton in February/March, i.e. during the late winter/early spring phytoplankton bloom, with Bosmina in March/ April, and with Daphnia in April/May, i.e. during the periods of population increase of the two herbivores. In both lakes the response windows of water temperatures and of herbivores overlapped temporally, but those of phytoplankton and herbivores did not.

The start of the clear-water phase differed significantly between the two lakes ( $t$-test: $t=3.9, P<0.001)$ and occurred on average in Müggelsee [minimum phytoplankton biovolume on Julian day $147 \pm 3.6 \mathrm{~d}(\mathrm{SE})]$ two to three weeks earlier than in Lake Constance (minimum phytoplankton biovolume on Julian day $165 \pm 3.6 \mathrm{~d}$ ). The start of the clear-water phase in Lake Constance was significantly related to the start of the clear-water phase in Müggelsee (Fig. 5, $r=0.63, P<0.05$ ).

\section{Discussion}

Lake size is considered to be an important factor influencing food-web structure and regulation of lakes, 

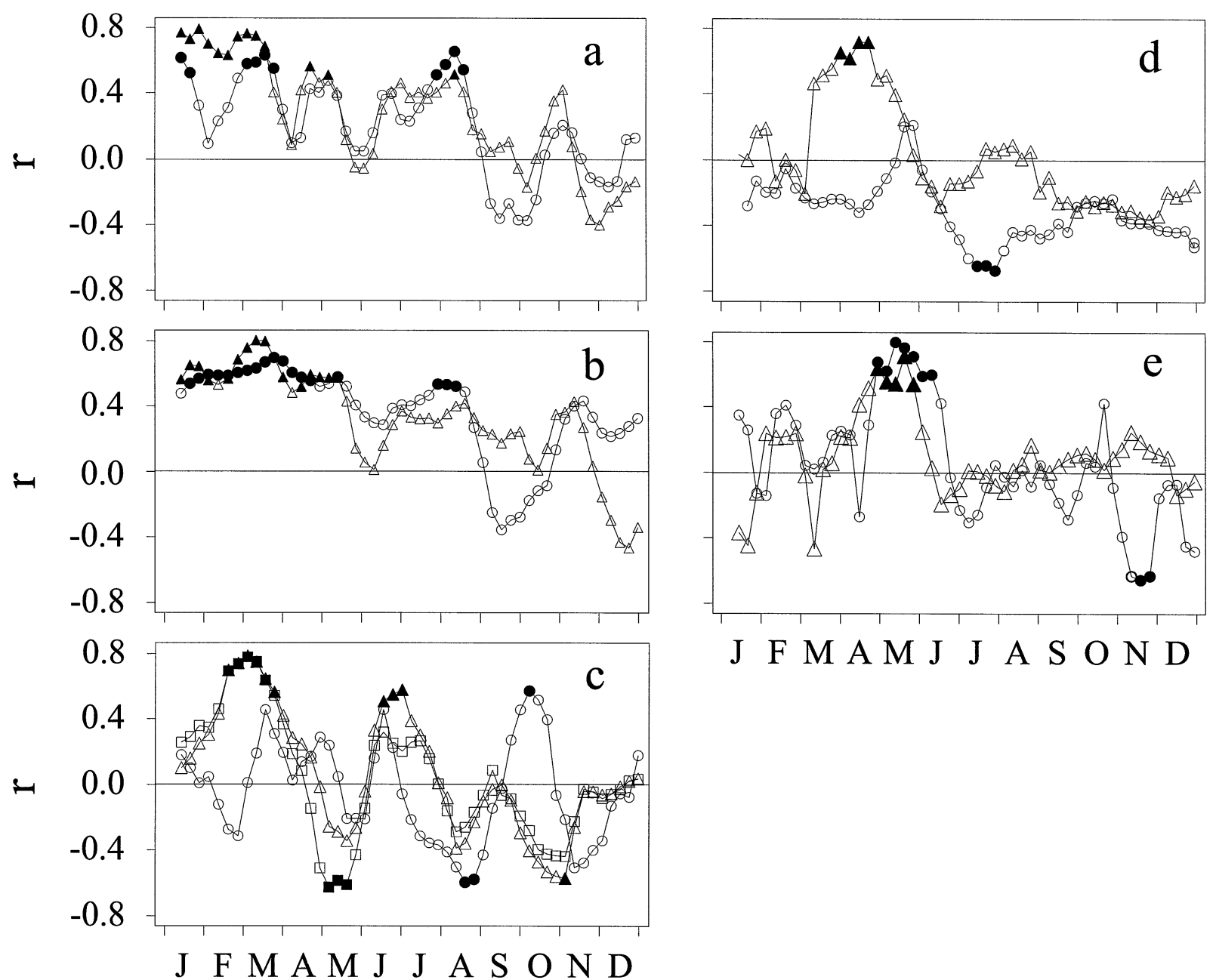

Fig. 3 Correlograms between the NAO index and four-week moving averages of (a) air temperature (b) water temperature (c) phytoplankton biovolume (d) Bosmina abundance, and (e) Daphnia abundance in Müggelsee (triangles) and Lake Constance (circles). Additionally, correlation coefficients between the NAO and Müggelsee phytoplankton excluding cyanobacteria is shown (Fig.3c, squares). Solid symbols indicate correlations significant at $P<0.05$.

and entire monographs (Tilzer \& Serruya 1991) and textbooks (Scheffer 1998) have been devoted to the ecology of large vs. small lakes. For example, the higher proportion of littoral habitats compared to total lake area that exists in small lakes provides a larger potential for littoral zone feeding of fishes, resulting in increased fish biomass per unit area and increased predation pressure of fish on zooplankton (Schindler etal. 1996). Additionally, there is evidence for an increased ratio of autotrophic to heterotrophic plankton biomass in small as compared to large lakes (Straile 1998), which may provide herbivores in small lakes with an increased abundance of food. Considering these differences, the results obtained for Müggelsee in respect, for instance, to the interannual variability of Daphnia abundance, are surprisingly similar to the results obtained for Lake Constance. This exemplifies the important role of meteorological forcing in causing interannual variability in the seasonal succession dynamics of lakes, at least until the start of the clear-water phase.

In addition to the observed significant relationships of various parameters in winter, spring and early summer to the NAO index, we also observed several significant correlations from June onwards in both lakes. The reasons for these correlations are not clear at present. The discussion will hence focus on the effects of the NAO on the plankton dynamics up to the start of the clearwater phase.

For Lake Constance, the analysis of temporal forcing of Daphnia abundances largely confirmed former results from an analysis of Daphnia biomass (Straile \& Geller 1998a; Straile 2000). During late winter and early spring, growth of Daphnia is severely restricted by low food concentrations and low temperatures. After the onset of 


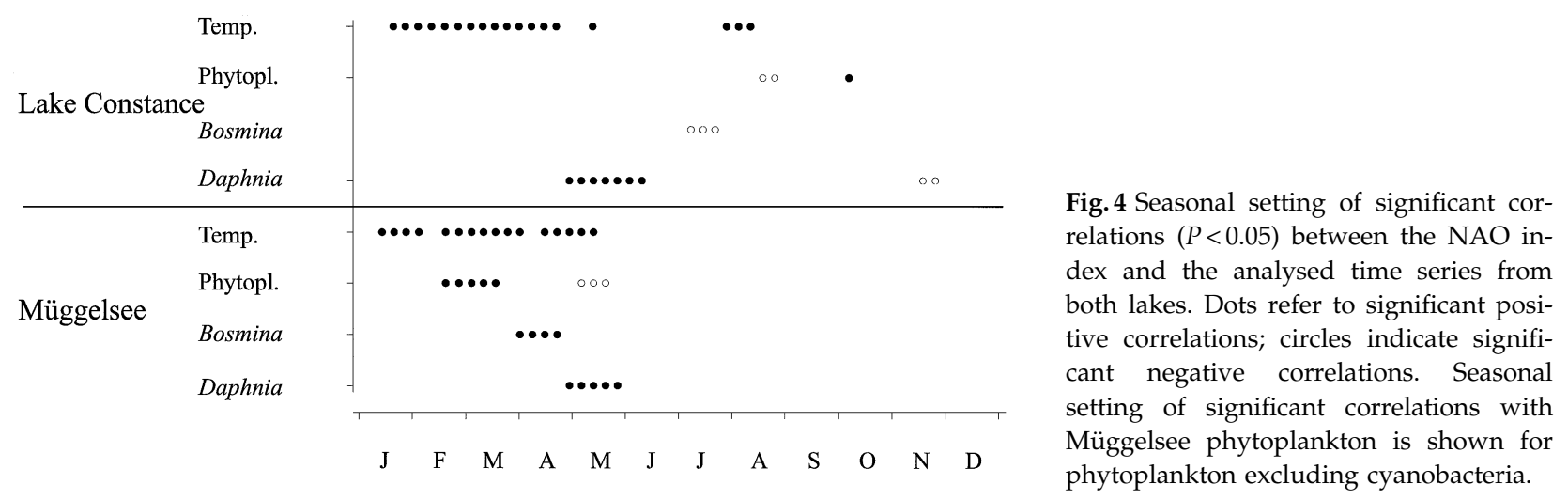

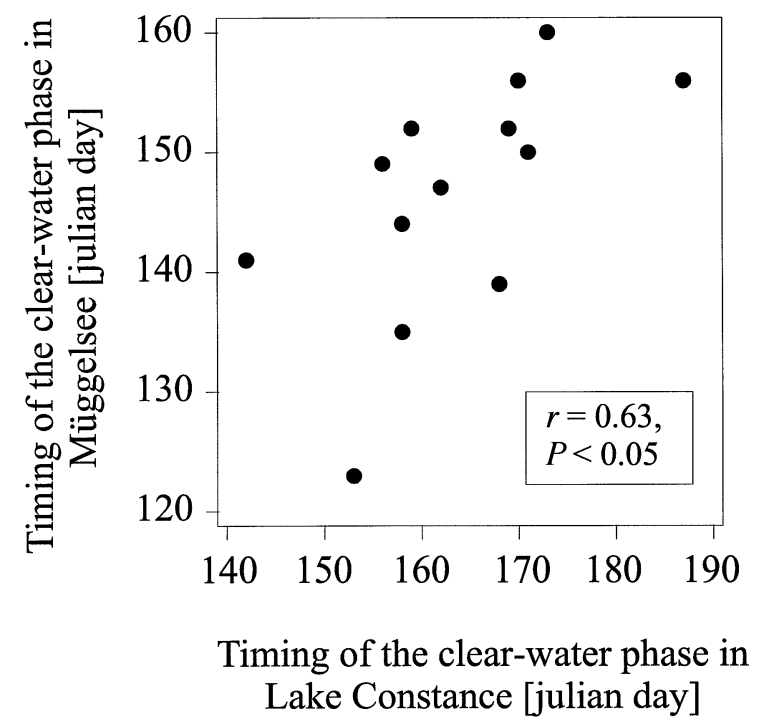

Fig. 5 Relationship between the timing of the clear-water phase in both lakes. Years with no clear-water phase in Müggelsee $(1980,1985,1986,1988,1989)$ were excluded.

stratification, this 'colimitation' switches to a temperature control of Daphnia growth, because water temperature increases more slowly than phytoplankton biovolume (Gaedke etal. 1998; Straile 2000). Despite a much higher overall phytoplankton biovolume in Müggelsee and a response of phytoplankton to the NAO as early as February in Müggelsee, the response of Daphnia to the NAO was delayed until April/May, when increased temperatures allowed substantial population growth. This resulted in a separation of the response windows, i.e. a decoupling of phytoplankton and Daphnia. The faster vernal increase of water temperatures in Müggelsee than in Lake Constance resulted in higher daphnid abundances in spring in Müggelsee (Fig. 2e). Furthermore, using an ANCOVA with Daphnia abundances during May as the dependent variable and the NAO as the independent variable revealed significant differences between the lakes, i.e. 'lake' contributes significantly to the model (Fig. 6a). An ancova with May temperature as independent variable yielded no significant 'lake' effect (Fig.6b), i.e. differences in May Daphnia abundances between the lakes can be explained by differences in water temperatures. Hence, the Müggelsee data and the comparison between Lake Constance and Müggelsee support the hypothesis of the regulation of interannual Daphnia variability in spring by abiotic factors, e.g. temperature, and not by food concentration.

Owing to the faster growth response of Daphnia in Müggelsee, the clear-water phase started on average two to three weeks earlier there than in Lake Constance. Significantly negative correlations between the NAO and phytoplankton biovolume in Müggelsee in April additionally suggest an earlier negative influence of Daphnia on phytoplankton in this lake than in Lake Constance. Extensive blooms of cyanobacteria developed in Müggelsee around May in 1980, 1985, 1986, 1988 and 1989 (Nixdorf \& Hoeg 1993), i.e. independently of the NAO and Daphnia numbers, which, for example, were low in 1985 and high in 1989. Cyanobacteria are known to be less susceptible to zooplankton grazing. Possible mechanisms for this include the release of substances that inhibit the feeding activity of zooplankton (Haney et al. 1994) or the formation of colonies that may clog the filtration apparatus of, for example, daphnids (Gliwicz \& Lampert 1990). Consequently, the occurrence of cyanobacteria may result in high phytoplankton biovolume despite high Daphnia abundance. Hence, only when cyanobacteria were excluded did we find a significant negative relationship between phytoplankton biovolume and the NAO index during late April and early May (Fig.3c) and a negative relationship between phytoplankton biovolume and Daphnia abundance in Müggelsee during May (Fig. 7).

In contrast to the coherent response of water temperatures, daphnids, and the timing of the clear-water phase, there were differences in the response profiles of both lakes for phytoplankton and Bosmina. In Müggelsee, both were significantly related to the NAO index, whereas in 
Fig. 6 Scatterplot of mean Daphnia abundances in the Müggelsee (open circles) and Lake Constance (filled circles) in May vs. (a) the NAO Index (ANCOVA reveals significant effects of the NAO, $P<0.0001$ and significant differences between the lakes, $P<0.0005)$ and $(b)$ water temperatures in May (ANCOVA reveals significant effects of water temperature, $P<0.0005$, but no significant differences between the lakes, $P>0.1$ ).

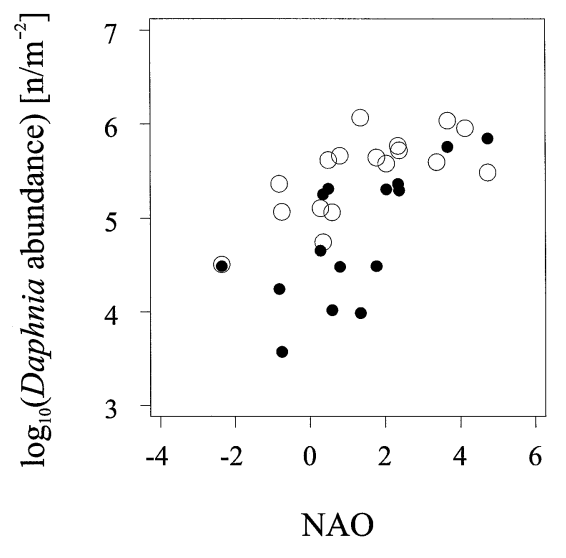

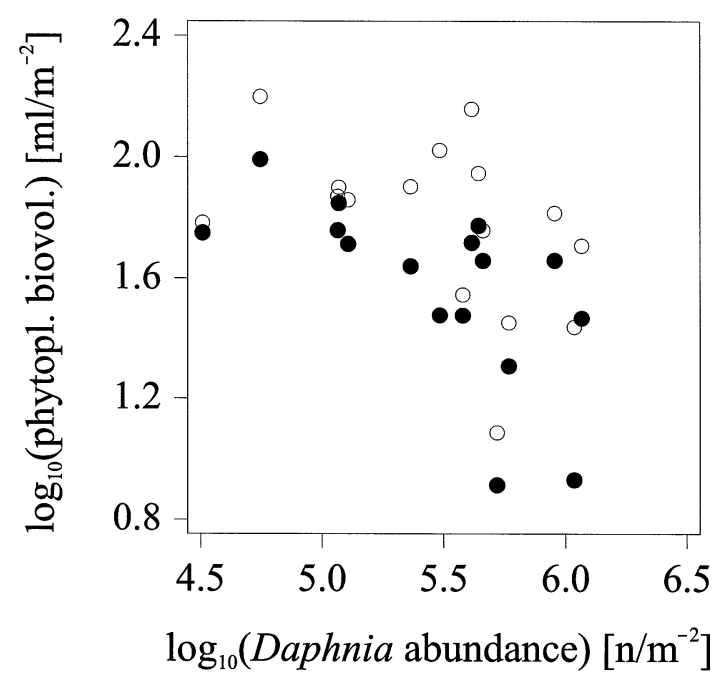

Fig. 7 Scatterplot of average Daphnia abundance vs. average total phytoplankton biovolume (circles, $r=-0.45, P<0.1$ ) and phytoplankton biovolume excluding cyanobacteria (dots, $r=$ $-0.63, P<0.01)$ during May in Müggelsee.

Lake Constance this was not the case. The strong positive relationship between the NAO index and phytoplankton biovolume in Müggelsee can be attributed to the lack of ice development in mild winters. Adrian et al. (1999) observed pronounced diatom blooms in Müggelsee during late winter/early spring of years with no ice cover, when increased turbulence favoured diatom growth. Lake Constance, however, was not covered by ice during the study period. In contrast, high rates of vertical mixing prevented the occurrence of a late winter/early spring bloom in Lake Constance, because phytoplankton growth in this lake is inhibited by a lack of thermal stratification strong enough to prevent the transport of algae below $20 \mathrm{~m}$ depth (Gaedke et al. 1998). Hence, the response of phytoplankton to meteorological forcing would seem to depend on lake depth.
In contrast to phytoplankton, the lack of a response of Bosmina to meteorological forcing in Lake Constance may reflect the effect of confounding variables. In contrast to Daphnia, Bosmina decreased strongly during the observation period in this lake, most probably as a result of ongoing re-oligotrophication (Straile \& Geller 1998b). This decline most probably outweighed the effects of the Bosmina response to meteorological forcing in Lake Constance. In Müggelsee, both Daphnia and Bosmina abundances during spring were related to the NAO index. However, significant positive relationships were observed as early as March for Bosmina and approximately one month later for Daphnia. This agrees with the observation that abundance peaks of Bosmina occur prior to abundance peaks of Daphnia in many lakes (Sommer etal. 1986) and may suggest that Bosmina is better adapted to lower temperatures.

To conclude, the comparative analysis of meteorological forcing revealed a difference in the responses of phytoplankton biovolume and Bosmina numbers to the NAO in Lake Constance and Müggelsee. Despite the difference in the response of primary producers, we found strong evidence for temporal coherence in Daphnia development during spring, due to the coherence in the vernal warming. In addition, early clear-water phases in Lake Constance were observed in years that also showed early clear-water phases in Müggelsee, when years with a strong development of cyanobacteria in Müggelsee were excluded. The temporal coherence over a large geographical region, despite large differences between the lakes, suggests that a great variety of lakes in central Europe may possibly have exhibited a similar interannual variability in the timing of successional events during the last 20 years. An additional example of this may be given by the plankton dynamics in Pluss-See, where a relationship between average winter temperatures and the timing of the clear-water phase has also been observed (Müller-Navarra et al. 1997). 


\section{Acknowledgements}

We would like to thank U. Gaedke, W. Geller, and D. Ollinger for providing the Lake Constance phytoplankton, zooplankton and water temperature data, and S. Hoeg and R. Rusche for the analysis of the Müggelsee phytoplankton and zooplankton samples. Dieter Gerten helped in assembling the Müggelsee data and Simon Linke helped with the data analysis. Thanks also to W. Nagl for statistical advice. Funding was supplied by the EU project 'Response of European Freshwater Lakes to Environmental and ClimaTic change (REFLECT, contract number: ENV4-CT97-0453)'. Comments by Ursula Gaedke, Erich Bäuerle, Tom Frost, Dieter Gerten, David M. Livingstone, and two anonymous referees greatly improved the style and content of the manuscript.

\section{References}

Adrian R (1997) Calanoid-cyclopoid interactions: evidence from an 11-year field study in a eutrophic lake. Freshwater Biology, 38, 315-325.

Adrian R, Deneke R (1996) Possible impact of mild winters on zooplankton succession in eutrophic lakes of the Atlantic European area. Freshwater Biology, 36, 757-770.

Adrian R, Deneke R, Mischke U, Stellmacher R, Lederer P (1995) A long-term study of the Heiligensee (1975-92). Evidence for effects of climatic change on the dynamics of eutrophied lake ecosystems. Archiv für Hydrobiologie, 133, 315-337.

Adrian R, Walz N, Hintze T, Hoeg S, Rusche R (1999) Effects of ice duration on plankton succession during spring in a shallow polymictic lake. Freshwater Biology, 41, 1-12.

Bartlett MS (1946) On the theoretical specification of sampling properties of autocorrelated time series. Journal of the Royal Statistical Society, Suppl. 8, 27-411.

Bäuerle E, Gaedke U (eds) (1998) Lake Constance Characterization of an ecosystem in transition. Archiv für Hydrobiologie, Special Issues: Advances in Limnology, 53, 610pp.

Belgrano A, Lindhal O, Hernroth B (1999) North Atlantic Oscillation, primary productivity and toxic phytoplankton in the Gullmar Fjord, Sweden (1985-96). Proceedings of the Royal Society of London, B, 266, 425-430.

Driescher E, Behrend H, Schellenberger G, Stellmacher R (1993) Lake Müggelsee and its environment - natural conditions and anthropogenetic impacts. Internationale Revue der Gesamten Hydrobiologie, 78, 327-343.

Fromentin J-M, Planque B (1996) Calanus and environment in the North Atlantic. II. Influence of the North Atlantic Oscillation on C. finmarchicus and C. helgolandicus. Marine Ecology Progress Series, 134, 111-118.

Gaedke U, Ollinger D, Bäuerle E, Straile D (1998) The impact of the interannual variability in hydrodynamic conditions on the plankton development in Lake Constance in spring and summer. Archiv für Hydrobiologie, Special Issues: Advances in Limnology, 53, 565-585.

Gliwicz ZM, Lampert W (1990) Food thresholds in Daphnia species in the absence and presence of blue-green filaments. Ecology, 71, 691-702.

Haney JF, Forsyth DJ, James MR (1994) Inhibition of zooplankton filtering rates by dissolved inhibitors produced by naturally occurring cyanobacteria. Archiv für Hydrobiologie, 132, 1-13.

Hurrell JW (1995) Decadal trends in the North Atlantic Oscillation: regional temperatures and precipitation. Science, 269, 676-679.

Hurrell JW, Van Loon H (1997) Decadal variations in climate associated with the North Atlantic Oscillation. Climatic Change, 36, 301-326.

Kröncke I, Dippner JW, Heyden H, Zeiss B (1998) Long-term changes in macrofaunal communities off Norderney (East Frisia, Germany) in relation to climate variability. Marine Ecology Progress Series, 167, 25-36.

Müller-Navarra DC, Güss S, Von Storch H (1997) Interannual variability of seasonal succession events in a temperate lake and its relation to temperature variability. Global Change Biology, 3, 429-438.

Nixdorf B, Hoeg S (1993) Phytoplankton - community structure, succession and chlorophyll content in Lake Müggelsee from 1979 to 1990. Internationale Revue der Gesamten Hydrobiologie, 78, 359-377.

Post E, Stenseth NC (1998) Large-scale climatic fluctuation and population dynamics of moose and white-tailed deer. Journal of Animal Ecology, 67, 537-543.

Reid PC, Edwards M, Hunt HG, Warner AJ (1998) Phytoplankton change in the North Atlantic. Nature, 391, 546.

SAS Institute (1988) SAS/STAT user's guide, release 6.03 edition. SAS Institute.

Scheffer M (1998). Ecology of Shallow Lakes. Chapman \& Hall, London.

Schindler DE, Carpenter SR, Cottingham KL et al. (1996) Food web structure and littoral zone coupling to pelagic trophic cascades. In: Food Webs: Integration of Pattern and Dynamics (eds Polis G, Winemiller K), pp. 96-105. Chapman \& Hall, New York.

Sommer U, Gliwicz ZM, Lampert W, Duncan A (1986) The PEGmodel of seasonal succession of planktonic events in fresh waters. Archiv für Hydrobiologie, 106, 433-471.

Straile D (1998) Biomass allocation and carbon flow in the pelagic food web of Lake Constance. Archiv für Hydrobiologie, Special Issues: Advances in Limnology, 53, 545-563.

Straile D (2000) Meteorological forcing of plankton dynamics in a large and deep continental European lake. Oecologia, 122, 44-50.

Straile D, Geller W (1998a) The response of Daphnia to changes in trophic status and weather patterns: a case study from Lake Constance. ICES Journal of Marine Science, 55, 775-782.

Straile D, Geller W (1998b) Crustacean zooplankton in Lake Constance from 1920 to 1995: response to eutrophication and reoligotrophication. Archiv für Hydrobiologie, Special Issues: Advances in Limnology, 53, 255-274.

Tilzer MM, Serruya C (eds) (1991). Large Lakes - Ecological Structure and Function. Springer, Berlin.

Tunberg BG, Nelson WG (1998) Do climatic oscillations influence cyclical patterns of soft bottom macrobenthic communities on the Swedish west coast? Marine Ecology Progress Series, 170, 85-94. 